\title{
Inducible expression of Pisum sativum xyloglucan fucosyltransferase in the pea root cap meristem, and effects of antisense mRNA expression on root cap cell wall structural integrity
}

\author{
Fushi Wen · Rhodesia M. Celoy · Trang Nguyen • \\ Weiqing Zeng $\cdot$ Kenneth Keegstra $\cdot$ Peter Immerzeel • \\ Markus Pauly $\cdot$ Martha C. Hawes
}

Received: 18 October 2007/Revised: 31 January 2008/Accepted: 20 February 2008/Published online: 18 March 2008 (c) Springer-Verlag 2008

\begin{abstract}
Mitosis and cell wall synthesis in the legume root cap meristem can be induced and synchronized by the nondestructive removal of border cells from the cap periphery. Newly synthesized cells can be examined microscopically as they differentiate progressively during cap development, and ultimately detach as a new population of border cells. This system was used to demonstrate that Pisum sativum L. fucosyl transferase (PsFutl) mRNA expression is strongly expressed in root meristematic tissues, and is induced $>2$-fold during a 5 -h period when mitosis in the root cap meristem is increased. Expression of PsFut1 antisense mRNA in pea hairy roots under the control of the CaMV35S promoter, which exhibits meristem localized expression in pea root caps, resulted in a $50-60 \%$ reduction in meristem localized endogenous PsFut1 mRNA expression measured using whole mount in situ hybridization. Changes in gross levels of cell wall fucosylated xyloglucan were not detected, but altered
\end{abstract}

Communicated by G. May.

F. Wen · R. M. Celoy · T. Nguyen · M. C. Hawes ( $\)$

Division of Plant Pathology and Microbiology,

Department of Plant Sciences, Forbes Hall,

University of Arizona, Tucson, AZ 85721, USA

e-mail: mhawes@u.arizona.edu

W. Zeng

Department of Plant Biology, Michigan State University,

East Lansing, MI 48824, USA

K. Keegstra $\cdot$ M. Pauly

Department of Energy Plant Research Laboratory,

Michigan State University, East Lansing, MI 48824, USA

P. Immerzeel

Plant Cell Wall Group, Max-Planck Institute for Molecular Plant

Physiology, Am Mühlenberg 1, 14476 Golm, Germany surface localization patterns were detected using whole mount immunolocalization with CCRC-M1, an antibody that recognizes fucosylated xyloglucan. Emerging hairy roots expressing antisense PsFut1 mRNA appeared normal macroscopically but scanning electron microscopy of tissues with altered CCRC-M1 localization patterns revealed wrinkled, collapsed cell surfaces. As individual border cells separated from the cap periphery, cell death occurred in correlation with extrusion of cellular contents through breaks in the wall.

Keywords Fucose $\cdot$ Cell walls $\cdot$ Hairy roots · Root cap meristem

\section{Introduction}

The purpose of this study was to characterize expression of Pisum sativum fucosyltransferase (PsFut1) mRNA during primary cell wall synthesis, and to examine the impact of gene silencing using transgenic clonal pea hairy roots. The plant cell wall consists of a primary wall, middle lamella and, in some cells, a secondary wall (Albersheim et al. 1994; Carpita et al. 2001; Lerouxel et al. 2006; McCann and Roberts 1991). These interacting parts are comprised of the complex polysaccharides cellulose, hemicellulose and pectin, and more than 100 proteins (Bauer et al. 1973; McQueen-Mason et al. 1992; Pauly et al. 1999; Somerville et al. 2004; Varner and Lin 1989; Wen et al. 2007; Zhu et al. 2006). Dissecting how the cell wall is assembled is complicated by the fact that its synthesis begins with primary wall assembly during the early moments of cell division and continues throughout the life of the cell in response to developmental and environmental stimuli (Cosgrove 2005; Carpita and Gibeaut 1993; Dhugga 2005; Freshour et al. 
1996; Johansen et al. 2006; Ookawara et al. 2005; Varner and Lin 1989). Proteins within the cell wall include cell wall modifying enzymes that alter wall structure as the cell matures (Cassab and Varner 1988; Guillen et al. 1995; Maldonado-Mendoza et al. 2005; Romo et al. 2005; Van Loon et al. 2006; Ye et al. 2006). Even in a mature plant cell, a brief treatment with an elicitor triggers cross-linking that fundamentally changes the relationship of proteins to the rest of the cell wall components (Brisson et al. 1994).

Pea and other legumes have been used for decades as a model to establish fundamental principles of cell wall composition, structure, and function (Brisson et al. 1994; Callaghan and Benziman 1984; Guillen et al. 1995; Hayashi 1989, 1991; Kauss and Hassid 1967; Keller et al. 1988; Lin et al. 1991; Satiat-Jeunemaitre et al. 1992; Selvendran 1975; Takeda et al 2002; Terry et al. 1981; York et al. 1984). Within pea cell walls, xyloglucan comprises ca $20 \%$ of the weight of the cell wall (Hayashi 1989). In addition to a structural role, soluble components of xyloglucan such as fucosylated xyloglucan oligosaccharides have been shown to exhibit hormone-like signalling activities during cellular elongation in pea (Fry 1989; Fry et al. 1993a; Popper and Fry 2005; York et al. 1984). Pisum sativum xyloglucan fucosyltransferase (PsFUT1) is among a small number of cell wall biosynthetic enzymes whose function has been characterized (Faik et al. 1997). This microsomal enzyme was isolated from pea epicotyls and shown to synthesize an alpha-1,2 fucose:galactose linkage by in vitro fucosylation of xyloglucan from tamarind seeds, with GDP-fucose as a donor (Perrin et al. 1999). The PsFUT1 sequence was used to identify and evaluate a related gene family in Arabidopsis (Perrin et al. 2003; Sarria et al. 2001; Vanzin et al. 2002). Isolation of the PsFutl gene from pea and confirmation of its biochemical activity and substrate specificity was carried out (Faik et al. 2000). To date, PsFutl expression patterns and the impact of gene silencing in pea have not been evaluated.

The root cap in pea and other legumes provides a convenient model to examine the role of altered gene expression in plants because normal development can be induced and synchronized nondestructively (Feldman 1984; Hawes et al. 2003). Root cap development is controlled by an extracellular signal secreted from border cells (Hawes and Lin 1990). Within 5 min after removing border cells from the cap periphery by gentle agitation of the root tip in water, increased mitosis can be detected within the root cap meristem concomitant with a global switch in gene expression throughout the cap (Brigham et al. 1998). Mitosis in the meristem remains at an elevated level for $5 \mathrm{~h}$ as a new set of $3,500 \pm 500$ cells is made to replace the harvested border cells, and then returns to baseline values (Brigham et al. 1998; Hawes and Lin 1990). Newly synthesized cells differentiate progressively through specialized cell layers dedicated to starch synthesis, gravity sensing, mucilage production and cell separation, and these developmental stages can be readily distinguished morphologically (Feldman 1984). A new set of border cells is present on the cap periphery after $24 \mathrm{~h}$, at which time cap turnover ceases and mitosis remains blocked at the G2M phase of the cell cycle indefinitely, until cap turnover is again induced. Stage-specific localized expression of specific genes associated with processes including cell division, cell wall synthesis, starch synthesis, and cell wall separation has been profiled using this system (Brigham et al. 1998; Wen et al. 1999, 2004, 2005, 2007; Woo and Hawes 1997; Woo et al. 1999, 2003, 2007), The use of transgenic hairy roots allows efficient use of gene silencing in clonal tissue that can be amplified rapidly for detailed cellular, molecular and chemical analysis $(\mathrm{Hu}$ and $\mathrm{Du}$ 2006).

In this study, we measured the expression of PsFutl mRNA in pea root caps during the induction of mitosis and cap turnover, and evaluated the impact of PsFut 1 antisense mRNA expression in transgenic clonal hairy roots.

\section{Materials and methods}

\section{Plant material}

Pea (Pisum sativum cv Little Marvel, Royal Seed Company) seeds were surface sterilized with $95 \%$ ethanol for 10 min followed by immersion in $5.25 \%$ sodium hypochlorite for $30 \mathrm{~min}$, as described (Hawes and Lin 1990). Seeds were rinsed $5 \times$ with sterilized water and seeds that floated to the surface, were discoloured, or obviously damaged were culled during a 6-h period of imbibition in sterile distilled water (Hawes and Lin 1990). Imbibed seeds were placed onto $1 \%$ water agar (Bacto ${ }^{\mathrm{TM}}$ Agar, Becton Dickinson and Company) in sterilized magenta jars, and then were incubated at $24^{\circ} \mathrm{C}$ for $2-3$ days or until the stem was $1-2 \mathrm{~cm}$ high. Germinated seedlings were transferred to $24^{\circ} \mathrm{C}$ in a $16 \mathrm{~h}$ light intensity growth chamber for two more days.

\section{Construction of sense and antisense pBIPsFut1} transgenes constructs

The 1,698 bp PsFutl gene fragment in pGEMT-easy vector was amplified using polymerase chain reaction (PCR), with primers containing created restriction sites for cloning. The PCR-amplified fragment was digested by corresponding restriction enzymes and then inserted in both sense and antisense orientations under the control of the cauliflower mosaic virus (CaMV) promoter in vector pBI121 whose uidA gene was removed. The resulting constructs $p B I P s$ Fut $1 S$ and $p B I P s F u t 1 A$ were mobilized into Agrobacterium 
rhizogenes R1000nal through triparental mating using $\mathrm{p} R K 2013$ as helper strain and kanamycin as selectable marker (Wen et al. 1999; Woo et al. 1999).

\section{Southern and Northern blot analysis}

Southern blot analysis of pea genomic DNA was carried out according to standard procedures (Sambrook et al. 1989). PsFutl mRNA levels in root tips at different time points after removing border cells were detected by RNA blot analysis using ${ }^{32} \mathrm{P}$-labelled single strand PsFutl transcript as probe. A single strand RNA probe (riboprobe) was synthesized according to Maxiscript in vitro transcription kits (Ambion, Austin, TX). Northern blot analysis was also carried out to compare PsFutl mRNA levels in wild type hairy roots with that in hairy roots expressing PsFutl antisense mRNA. A single strand RNA probe (riboprobe) was synthesized according to Maxiscript in vitro transcription kits (Ambion, Austin, TX). Samples were processed by standard procedures, as described (e.g. Wen et al. 1999; Woo et al. 1999).

Transgenic clonal root culture development and maintenance

Hairy root clones were transformed using full-length sense and antisense mRNA, as described (Wen et al. 1999). Individual hairy roots induced by $A$. rhizogenes with the pBIPsFutl antisense plasmid, and hairy roots induced by the A. rhizogenes R1000nal strain (wild type) were grown on Gamborg's B-5 (B5) basal medium, supplemented with carbenicillin $(50 \mu \mathrm{g} / \mathrm{ml})$ to eliminate $A$. rhizogenes. Transformed roots were selected by plating individual, excised roots (ca $1 \mathrm{~cm}$ in length) onto medium containing kanamycin; cultures then were amplified by growth on B5 medium for 2 weeks.

Transformation of individual hairy root lines was confirmed by PCR amplification of the target sequence. Total chromosomal DNA was isolated from the hairy root clones using the DNeasy plant mini kit (Qiagen). Kanamycin primers (left and right) were used and PCR conditions of $1 \times: 95^{\circ} \mathrm{C} 5 \mathrm{~min}, 35 \times: 95^{\circ} \mathrm{C} 30 \mathrm{sec}, 50^{\circ} \mathrm{C}$ $30 \mathrm{sec}, 72^{\circ} \mathrm{C} 30 \mathrm{sec}, 1 \times: 72^{\circ} \mathrm{C} 5 \mathrm{~min}$ for the pBIPsFut 1 antisense samples. PCR products were analyzed by $1 \%$ agarose gel electrophoresis. Hairy root lines were maintained on $\mathrm{B} 5$ medium at $24^{\circ} \mathrm{C}$ in the dark and subcultured by transferring individual root tips onto fresh medium at 2 to 4 -week intervals.

Cell wall analysis

Oligosaccharide mass profiling (OLIMP) (Lerouxel et al. 2002) was used to compare wild type hairy roots from clonal lines transformed with R1000nal only, or from two independent lines expressing PsFutl antisense mRNA (PsFutlAS1 or PsFutlAS2). Excised roots, root tips (1-2 $\mathrm{mm}$ from the apex), or border cells were stored and transported in reaction tubes with ethanol. Root material was transferred to a screw capped Eppendorf tube together with a metal ball and transferred into liquid nitrogen. Tissue was ground in a Retsch MM200 grinder (Retsch $\mathrm{GmbH} \&$ Co., KG, Haan, Germany) for $1 \mathrm{~min}$ at $25 \mathrm{~Hz}$. The ground cell wall material was resuspended in $70 \%$ ethanol and centrifuged. The pellet was washed once in chloroform: methanol $(1: 1 \mathrm{v} / \mathrm{v})$ and dried. The pellet was incubated with xyloglucanase to release xyloglucan fragments for $17 \mathrm{~h}$ at $37^{\circ} \mathrm{C}$. The enzyme digest was centrifuged and the supernatant was analyzed by MALDITOF MS to characterize the formed xyloglucan oligosaccharides (Lerouxel et al. 2002; Pauly et al. 2001a, b). The spectra were statistically analyzed for differences in peak areas.

Whole mount in situ hybridization and immunolocalization

Whole mount in-situ hybridization (WISH) analysis of pea hairy roots was carried out as described (Brigham et al. 1998; Woo and Hawes 1997; Woo et al. 1999). pGEMTPsFut1 plasmids were extracted using standard procedures (Sambrook et al. 1989) from E. coli grown overnight in Luria broth at $37^{\circ} \mathrm{C}$.

Sense and antisense mRNA probes were prepared using the Digoxigenin (DIG)-UTP RNA labelling kit, according to the manufacturer's instructions (SP6/T7, Cat. \#1 175 025). Root tips of wild type hairy roots transformed with R1000 Agrobacterium rhizogenes and hairy roots induced by A. rhizogenes containing the pBIPsFutl antisense plasmid were excised $1.5 \mathrm{~cm}$ from the apex, then fixed and processed as described (Brigham et al. 1998). Both sense and antisense DIG-labelled probes (100-500 ng probe/mL) were used for gene expression analysis. Colorimetric detection was carried out with the DIG nucleic acid detection kit (Roche Cat. \# 1175 041).

Whole mount immunolocalization with the CCRC-M1 antibody was carried out as described in Freshour et al. (2003). The secondary antibody used is goat anti-mouse IgG-fluorescein isothiocyanate conjugate (Sigma, catalog No. F-0257). All the procedures of immunofluorescent labelling were done on unfixed roots cut $(1.5-\mathrm{cm}$ long with the root tip) in microfuge tubes with the change of corresponding buffers or reaction solutions. Unlabelled roots were included as negative controls to illustrate background yellow autofluorescence and its distinction from the bright green fluorescence seen in response to fluorescein labelling. 


\section{Results}

\section{PsFutl genes in Pisum sativum}

PsFut1 encodes a 1,2-fucosyltransferase, which shares 56$67 \%$ amino acid identity with its orthologue AtFut1 in Arabidopsis (Faik et al. 2000). The Arabidopsis FUT gene family includes nine additional closely related sequences (AtFut2-10) (Sarria et al. 2001). Southern blot analysis of pea genomic DNA at high stringency hybridization conditions revealed the existence of a small family of 2-3 sequences closely related to PsFutl (Fig. 1).

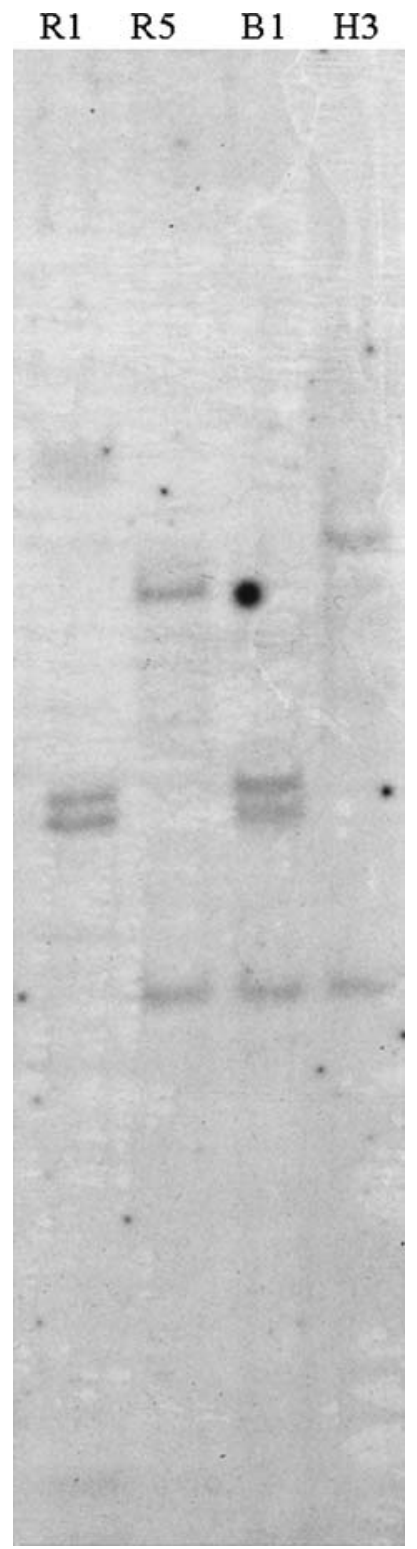

Fig. 1 Genomic Southern analysis of pea sequences related to Psfut1. Pea genomic DNA were digested with EcoRI (Rl), EcoRV (R5), BamHI (B1), or HindIII (H3) and probed with ${ }^{32} \mathrm{P}$-labelled Psfut at $55^{\circ} \mathrm{C}$
Increased meristem-localized PsFutl expression in correlation with induction of mitosis

Using the PsFutl sequence as a probe in Northern blot analysis, a single band was detected in root tips throughout the $\sim 24$-h period of root cap development from the onset of mitosis through maturation and separation of a complete set of new border cells (Fig. 2). There was a $>2$-fold increase in mRNA levels for several hours after removal of border cells (Fig. 2). This pattern of temporal expression is correlated with the period when new cells are being synthesized in the root cap (Brigham et al. 1998).

To evaluate spatial patterns of PsFutl mRNA expression in hairy roots, WISH was conducted (as in Woo and Hawes 1997; Brigham et al. 1998; Woo et al. 1999). The most intense labelling with PsFutl antisense mRNA in root tips of wild type hairy roots was localized within the apical and root cap meristematic regions (Fig. 3a, arrows). This pattern of localized expression is similar to that of reporter genes expressed in pea hairy roots under the control of the CaMV35S promoter, with moderate localized expression in the apical and root cap meristems but little or no expression in the root cap columella, periphery or border cells (Brigham et al. 1998; Nicoll et al. 1995). This promoter therefore was used to control expression of PsFut1 antisense mRNA in transgenic hairy roots to examine the

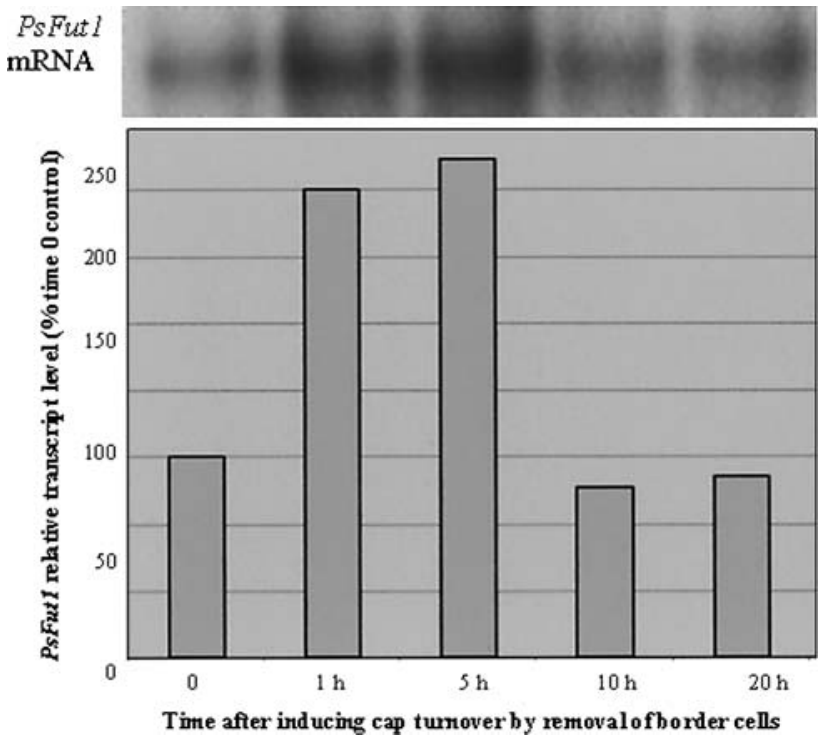

Fig. 2 Correlation between increased PsFut1 expression and induction of mitosis, which is optimal for $4-5 \mathrm{~h}$ after cap turnover is induced (Brigham et al. 1998). Density quantification of the signals obtained from the Northern blot analysis (top panel) was done using the NIH image software program (bottom panel). Relative level was determined based on the ratio of the density values obtained for the signal of interest compared with that of an actin control signal for the same evaluated RNA, and was normalized based on setting Time 0 as $100 \%$ 

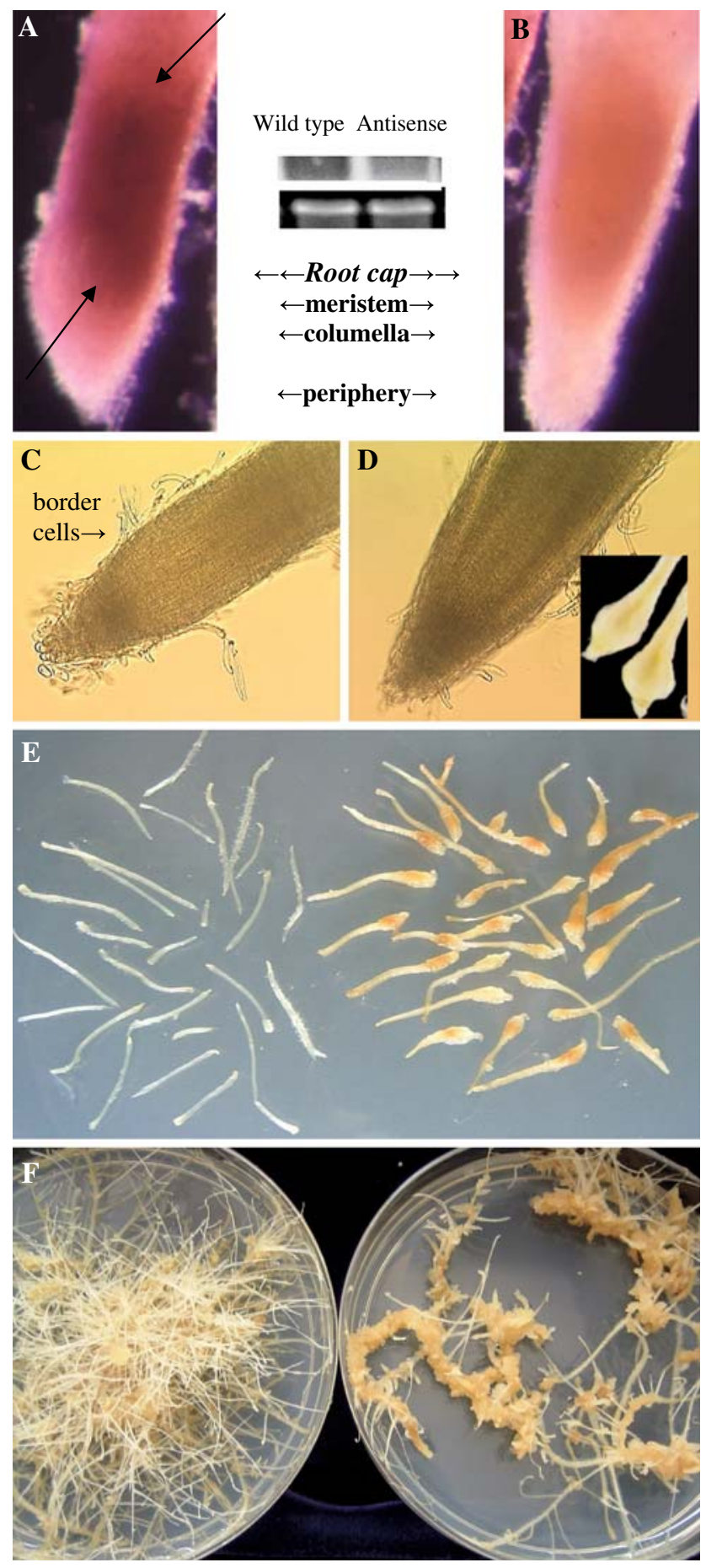

impact of reduced meristem localized expression of PsFut1 on root cell wall structure and function.

Deleterious effect of PsFutl antisense mRNA on recovery of transgenic hairy roots

Hairy roots expressing full length PsFut1 antisense mRNA were induced by inoculation with A. rhizogenes, and the frequency of transformation was compared with wild type
Fig. 3 Altered mRNA levels occurring in correlation with altered growth and development in transgenic hairy roots expressing PsFut 1 antisense mRNA. a, b Whole mount in situ hybridization (WISH); inset; Northern blot analysis of wild type and antisense hairy roots (top), with ribosomal RNA shown to illustrate equal loading (bottom). a PsFut1 expression in wild type hairy roots was localized predominantly within meristematic tissues; antisense mRNA probe (red-purple colour) strongly hybridized to the root cap and apical meristems; b Hybridization was significantly reduced in hairy roots expressing PsFut1 antisense mRNA; c Root tips of wild type hairy roots; d Root tips of hairy roots expressing PsFut1 antisense mRNA. Upon emergence, antisense root tips appear normal. Inset: as roots elongate, the region behind the tip swells; e Appearance of clonal wild type hairy roots (left) or hairy roots expressing Psfut 1 antisense mRNA; f Wild type hairy roots grow in culture indefinitely (left); in contrast, antisense hairy roots turn yellow, then brown as they transform into undifferentiated callus (right)

and vector only control lines. When pea stems are inoculated with $A$. rhizogenes expressing pBI121, 100\% of roots that develop are transformed with the Ri plasmid, and 40$50 \%$ also carry the transgene of interest and can be clonally propagated (Nicoll et al. 1995). In the current study, positive control hairy roots expressing CaMV35S::uidA were obtained at a frequency of $\sim 40 \%(45 / 105 ; 52 / 115$; 77/160) in three independent experiments. In contrast, frequency of transformation with PsFut1 antisense mRNA was only $4 \%(3 / 94 ; 8 / 190 ; 2 / 55)$.

Three transformed lines (PsFutlAS1, PsFutlAS2, and PsFutlAS3) were successfully amplified in culture. Density quantification of mRNA levels in PsFut1AS1 (Fig. 3b) and the other two lines (not shown) revealed that expression was reduced by $60-70 \%$ in individual hairy roots expressing PsFutl antisense mRNA, when compared with expression in wild type hairy roots (Fig. 3a). Northern blot analysis revealed similar reductions in expression (Fig. 3a, b, inset).

In each hairy root line expressing PsFutl antisense mRNA, similar morphological changes were observed. Emerging root tips of wild type hairy roots (Fig. 3c) appeared to be morphologically similar to root tips of antisense lines (Fig. 3d). However, as the root elongated, a bulge developed within the region of elongation in the antisense roots (Fig. 3d, inset). Whereas slight swelling developed at a frequency of $<1 \%(4 / 484 ; 1 / 199 ; 1 / 260 ; 0 /$ 128) on any given plate with wild type hairy roots of varying developmental stage, gross swelling was present on nearly $50 \%(46 / 99 ; 122 / 250 ; 97 / 199 ; 184 / 310)$ of antisense hairy roots under similar conditions and at the same developmental stages (Fig. 3e).

Cultured wild type pea hairy roots exhibit normal growth, development, and border cell production indefinitely (Fig. 3f, left). In contrast, hairy roots expressing PsFutl antisense mRNA converted to undifferentiated callus after 2-4 weeks (Fig. 3f, right).

The PsFutlASI antisense clonal line has continued to express the same phenotype for $>3$ years: new root tips 
continue to emerge and to appear normal initially, but elongating roots develop bulges within the region of elongation and convert to undifferentiated callus.

The PsFutlAS2 and PsFutlAS3 lines ceased to grow after 6 and 8 months in culture, respectively, at which time all roots developed into callus which turned brown, and ceased to develop further.

Altered patterns of fucosylated xyloglucan surface labelling in hairy roots expressing PsFutl antisense mRNA

To determine if these phenotypic changes were correlated with gross changes in fucosylated xyloglucan, oligosaccharide mass profiling (OLIMP) was used to compare products of cell wall digests from wild type and antisense hairy root tissues (Fig. 4). Levels of fucose containing xyloglucan oligosaccharides released by enzymatic digestion of excised root tips, region of elongation, or detached border cells of wild type or antisense hairy roots were not statistically distinct (Fig. 4). Because the test lines exhibited only partial inhibition of expression within the meristem, this result was not unexpected.

Changes in surface labelling patterns were detected using CCRC-M1, a monoclonal antibody that specifically recognizes $\alpha$-L-fucosylated xyloglucan (Freshour et al. 1996, 2003; Puhlmann et al. 1994). A yellow autofluorescence that occurs in pea roots under some conditions (Fig. 5a) is readily distinguishable from the bright green fluorescence seen using fluorescein (Fig. 5b) (Hawes 1983). The results revealed strong positive responses on all

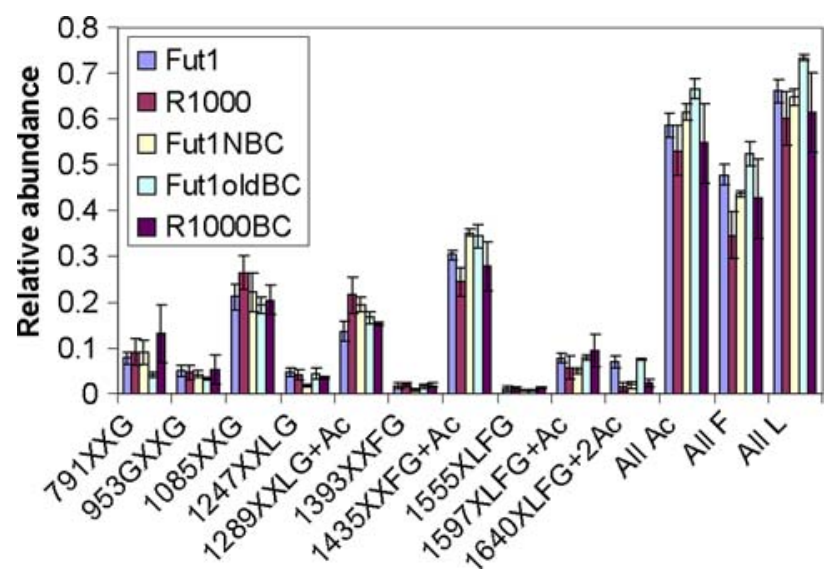

Fig. 4 Xyloglucan composition (relative amounts) of wild type hairy root tips (R1000), antisense root tips (FUT1), wild type border cells $(R 1000 B C)$, border cells from a new $(<1$ week) culture of antisense hairy roots $(F u t 1 N B C)$, and border cells from an older ( $>3$ weeks) culture of antisense hairy roots (Fut1OldBC) as analyzed by OLIMP $(n=3)$. The various xyloglucan oligosaccharides (XXG, XXXG, etc.) are presented in their one-letter code (Fry et al. 1993b) including mono- or di- $O$-acetylated species $(+\mathrm{OAc},+2 \mathrm{OAc})$ wild type pea hairy roots (Fig. 5b). These results were similar to patterns seen on Arabidopsis roots (Freshour et al. 1996, 2003). Surface labelling of pea hairy root tips expressing PsFutl antisense mRNA, by contrast, was variable among individual roots, with patterns distinct from that of wild type. There was an overall reduction in fluorescence in emerging root tips (Fig. 5c), with localized areas of very intense labelling at the periphery alternating with dark, non-reactive regions (arrow).

These data suggest that a change in distribution of fucosylated xyloglucan epitope occurred on the root surface in the antisense lines. The results obtained from pooled samples of complex tissues might obscure transient or localized changes in wall structure leading to phenotypic effects (Freshour et al. 2003). Individual hairy roots with altered CCRC-M1 labelling were subjected to a comparative microscopic analysis to assess possible phenotypes that were not obvious macroscopically.

Altered surface shape in root caps of hairy roots expressing PsFut1 antisense mRNA, revealed by SEM

Emerging root tips which appeared to be normal macroscopically or when examined at low magnification (Fig. 3c, d) but whose CCRC-M1 surface labelling patterns were altered compared with wild type (Fig. 5), were examined using SEM (Fig. 6). Root tips of wild type hairy roots retained size, shape, and contour after fixation and processing for SEM (Fig. 6a). In contrast, root tips from the PsFutlAS1 antisense hairy root line revealed obvious distortions in structure and mechanical integrity (Fig. 6b), with some localized areas collapsed (Fig. 6b, arrow). Similar results were reported previously in trichomes of Arabidopsis mur 2 mutant plants lacking fucosylated xyloglucan due to a mutation in AtFUT1 (Vanzin et al 2002). Whereas the trichomes appeared normal macroscopically, SEM analysis revealed wrinkled, collapsed surfaces. Similar results were seen with border cells (Fig. 6c, d). Whereas individual border cells from wild type hairy roots retained their shape after processing and fixation for SEM (Fig. 6c), border cells from antisense lines appeared collapsed and wrinkled (Fig. 6d).

Failure of cell wall structural integrity in individual border cells from hairy roots expressing PsFutl antisense mRNA

As border cells undergo cell separation at the cap periphery, they can be collected and examined as populations of single cells. Border cell viability in wild type pea hairy roots is $90 \pm 8 \%$, and border cell walls remain intact even after cells die (Hawes 1983). In contrast, no viable border cells were observed on any of the roots 

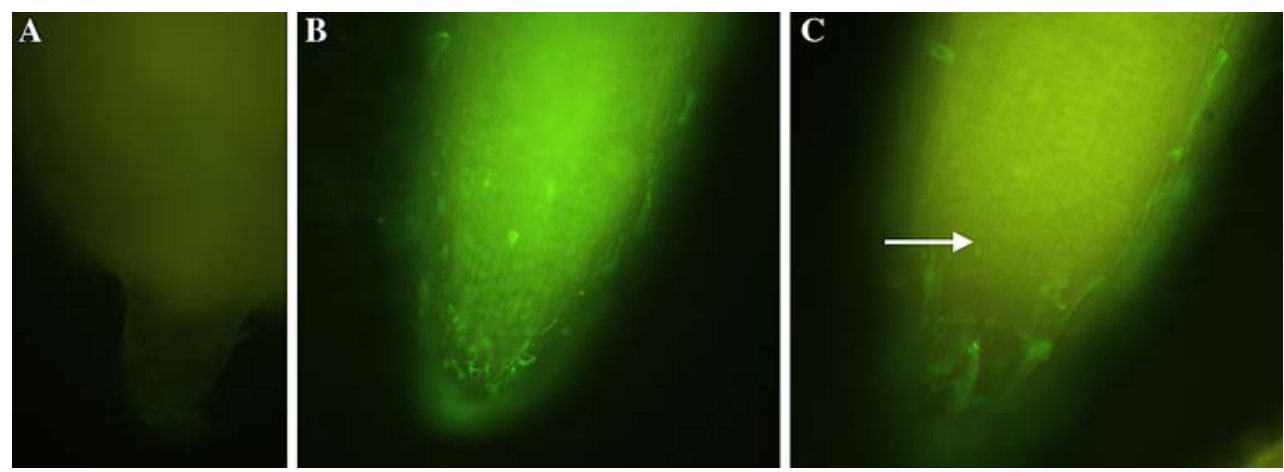

Fig. 5 Aberrant localization of surface fucosylated xyloglucan using CCRC-M1 in root tips of hairy roots expressing PsFut1 antisense mRNA. a Control hairy root expressing PsFut1 antisense mRNA, without exposure to CCRC-M1; a yellow autofluorescence is evident. b Root tip from wild type pea hairy root; strong labelling with CCRCM1 occurred uniformly over the entire root cap. The bright green fluorescence represents fluorescein-based immunolabelling. c Root tip from individual hairy roots expressing PsFut1 antisense mRNA; bright green fluorescence indicating a positive reaction was evident but varied in intensity among and within individual roots, with some regions exhibiting only yellow autofluorescence (arrow)
Fig. 6 Scanning electron microscopic comparison of root tips $(\mathbf{a}, \mathbf{b})$ versus border cells $(\mathbf{c}$, d) from wild type hairy roots (a, c) versus PsFut1 antisense mRNA lines $(\mathbf{b}, \mathbf{d})$
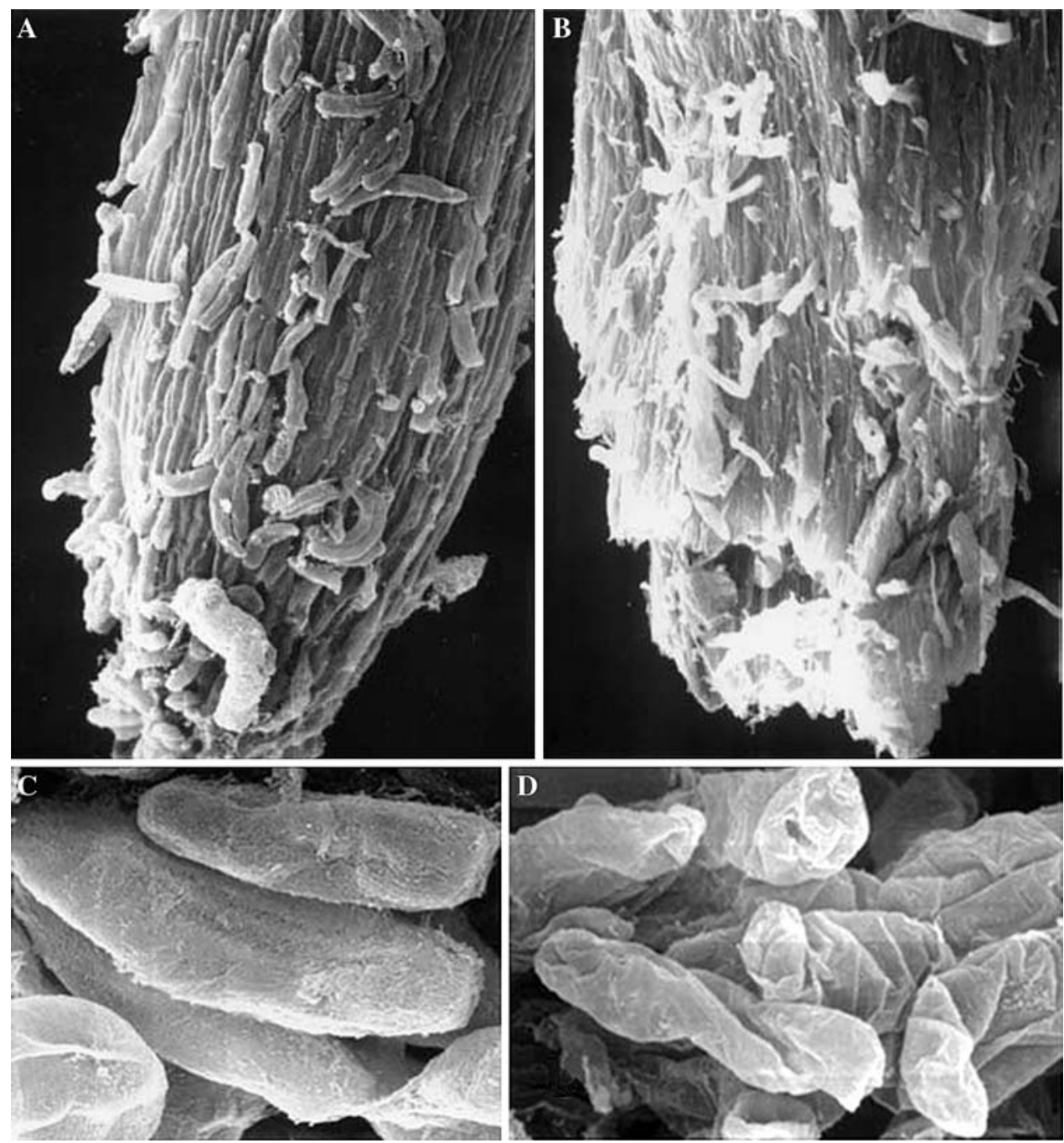

Microscopic analysis revealed that, as border cells detached, cell walls failed. Wild type border cells have uniformly thick $(\sim 1 \mu \mathrm{m})$ cell walls whose contours can be from antisense lines at any stage of development; viability among border cell samples from 45 roots examined was zero $(0 / 1,937$ cells $)$. 
Fig. 7 Altered structure and function in cell walls of border cells from three independent lines (PsFut1AS1, PsFut1AS2, PsFut1AS3) of hairy roots expressing PsFutl antisense mRNA. a Border cells of pea hairy roots, like those of normal roots, have rigid cell walls up to $1 \mu \mathrm{m}$ in diameter, the nucleus is prominent, and viability is $>90 \%$; b Border cells of antisense line PsFut1AS2 were extremely thin and fragile; cells from PsFut1AS3 (inset) were twisted and misshapen, with some wall regions having nearnormal width (arrow), adjacent to regions with visible holes (triangle); c Border cells from PsFut1AS1 exhibited regions of structural derangement, appearing to swell (arrows); d Cytoplasmic contents were extruded through holes in the walls of PsFut1AS1 border cells
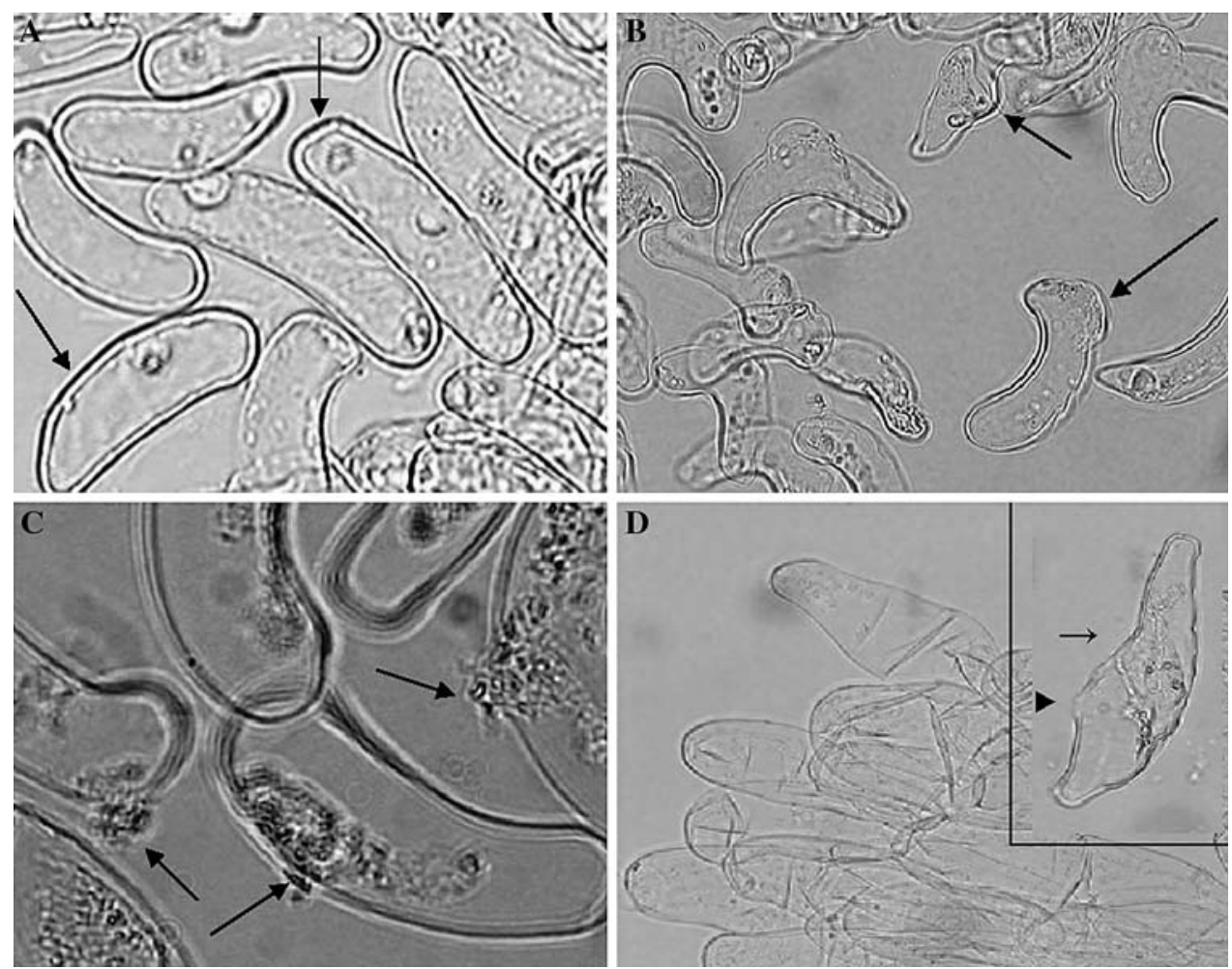

visualized (Fig. 7a, arrows). Nuclei and other cellular contents are intact and cytoplasmic streaming is readily apparent. Cell walls in all border cells (100/100) of all roots (100/100) examined from each of three independent antisense lines were morphologically distinct from those of wild type border cells (Fig. 7b-d).

PsFut1AS1 border cell walls exhibited irregular contours and sudden conspicuous bulges (Fig. 7b, arrows). Cytoplasm was retained in many PsFut1AS1 cells, but in others contents could be seen to be extruded through defects in the wall (Fig. 7C, arrows).

The lines with more extreme developmental derangement-PsFutlAS2 and PsFut1AS3 - also had more severe changes in border cell wall phenotypes (Fig. 7d). PsFut1 AS2 border cell walls were thin, the nucleus was only observed in a few cells, and most cells were devoid of cellular contents (Fig. 7d). PsFut1AS3 border cells were devoid of cytoplasmic bodies and were almost unrecognizable as plant cells (Fig. 7d, inset). Cell walls had some regions with normal thickness (Fig. 7d, inset, arrow) adjacent to visible breaks with cytoplasm extruded outward (Fig. 7d, inset, triangle).

\section{Discussion}

The capacity to synchronously induce root cap development facilitates identification of genes associated with specific processes that occur in morphologically distinct stages (Barlow 1975). For example, subtractive hybridization of pea root caps during the 5-min window when mitosis is induced was used to identify several meristem localized genes whose expression changes in correlation with the cell cycle (Woo and Hawes 1997). Psugt1, a meristem localized glycosyltransferase (GT) encoding gene whose expression is induced just prior to increased mitosis, was initially suspected to be involved in cell wall synthesis but its expression pattern was not consistent with such a function (Woo et al. 1999). The encoded enzyme ultimately proved instead to be a Family 1 GT controlling cell cycle regulation (Kamra et al. 2005; Woo et al. 2003, 2007). The inducible pea root cap system also was used in conjunction with transgenic hairy roots to identify a cap periphery localized pectin methylesterase (RcPME1) and to document for the first time that PME activity is necessary for cell separation (Wen et al. 1999; Zhu et al. 2004). Starch synthase expression was found to be localized only within cells of the central columella where amyloplasts are assembled (Brigham et al. 1998).

In the current study, pea hairy roots were used to characterize PsFutl expression during root cap development. The results revealed, for the first time, that PsFut 1 mRNA levels increase by $>2$-fold in correlation with increased mitosis and remain at an increased level throughout the 5-h period while new cells are synthesized. Expression occurred at a constitutive background level throughout the maturation process as cells differentiate in the root cap. WISH analysis revealed that PsFut1 
expression was predominantly localized within the root and root cap meristems but expression also occurred, at a lower level, within the body of the cap. These patterns are consistent with those predicted for an enzyme with roles in primary wall assembly as well as cell wall maturation.

Transgenic hairy roots expressing full length PsFut1 antisense mRNA under the control of the CaMV35S promoter, whose expression in pea hairy roots is localized to the root cap meristem, were developed. Macroscopic appearance of root caps appeared to be normal, but when processed for SEM and examined, the tissue was found to exhibit a wrinkled, collapsed appearance. This phenotype was strikingly similar to that previously found in trichomes of mur2 Arabidopsis mutant plants (Vanzin et al. 2002). These surface tissues also appeared macroscopically normal, but SEM revealed a wrinkled, collapsed appearance. The mur 2 mutant was selected based on altered levels of fucose in lines successfully recovered after T-DNA insertion (Reiter et al. 1993, 1997). The plants have a T-DNA insertion in the AtFUT1 locus and chemical analysis failed to identify measurable fucosylated xyloglucan from bulk root, shoot, stem, and flower tissue (Vanzin et al. 2002). The appearance of these tissues is macroscopically similar to that of wild type plants, and tensile strength and growth is normal (Reiter et al. 1997; Vanzin et al. 2002). It is possible that subtle defects might have been overlooked, or that deleterious effects of altered gene expression in whole plants may have masked by unknown compensatory mechanisms (Albersheim et al. 1994; Sarria et al 2001; Zablackis et al. 1996). On the other hand, different plant species or tissues have divergent cell wall structures and fucosylated xyloglucan undoubtedly plays a more critical role in some cells than in others; indeed, this epitope is naturally lacking in some plant tissues (Perrin et al. 1999).

Our data suggest that in pea, even down-regulation of PsFut1 mRNA and/or the closely related species detected in the pea genome, is deleterious to root development. Recovery of transformed hairy root lines expressing PsFut1 antisense mRNA was reduced dramatically compared with vector-only controls, and development in those, which were recovered, was altered. Within individual clonal pea hairy roots, the observed phenotypic changes increased in severity and ultimately proved lethal, and two of three independent lines expressing PsFutl antisense mRNA ceased to be culturable within 6-8 months. The mechanism for the observed changes is unclear but is not correlated with the wholesale loss of fucosylated xyloglucan reported in bulk stem, root, and floral tissues of the mur2 mutants (Vanzin et al. 2002). Antisense mRNA under the control of the CaMV35S promoter does not completely inhibit endogenous PsFutl expression in the root cap meristem, and expression ceases in cells beyond the root cap meristem (Nicoll et al. 1995; Wen et al. 1999; Woo et al. 1999). Because PsFutl expression occurs at a low level throughout the cap, a complete absence or even major reduction in amount of fucosylated xyloglucan would not necessarily be expected, and absolute amounts may be less important in structural integrity than accurate timing and localization of its deposition (van Hengel and Roberts 2002).

Closely related gene family members identified in Southern blot analysis could not be distinguished in Northern blot analysis of root caps but the possibility that PsFutl antisense mRNA expression altered the expression of other genes which contributed to the observed effects cannot be ruled out. The full range of natural substrates of most modifying enzymes, including PsFutl, are not known with certainty. Putative PsFutl-related genes in pea, even if they do prove to encode fucosyltransferases, could contribute to the observed changes by altering fucosecontaining molecules that are not a component of cell wall xyloglucan (Freshour et al. 2003). Fucose is a component of pea root cap mucilage and soluble root exudates, for example (Knee et al 2001). Soluble fucosylated oligosaccharides are potent signalling molecules in mammals as well as in plants, and changes in such metabolites could account for the pleiotropic effects observed in PsFut1 antisense hairy roots (McDougall and Fry 1989, 1990; Mejias-Luque et al. 2007; York et al. 1984).

Acknowledgments This study is based in part on the Master's thesis of R.M. Celoy (2002) University of Arizona, Tucson, AZ. The authors gratefully acknowledge the gift of CCRC-M1 antibody from Michael Hahn, CCRC, University of George, Athens GA. This study was supported by grant\# DE-FG02-04ER15551 from the Department of Energy, Division of Energy Biosciences, and the University of Arizona College of Agriculture and Life Sciences.

\section{References}

Albersheim P, An JH, Freshour G, Fuller MS, Guillen R, Ham KS, Han MG, Huang J, O'Neil M, Whitecombe A, Williams MV, York WS, Darvill A (1994) Structure and function studies of plant cell wall polysaccharides. Biochem Soc Trans 22:374-378

Barlow PW (1975) The root cap. In: Torrey JG, Clarkson DT (eds) The development and function of roots. Academic Press, London, pp 21-54

Bauer WD, Talmadge KW, Keegstra K, Albersheim P (1973) Structure of plant cell walls. 2. Hemicellulose of walls of suspension cultured sycamore cells. Plant Physiol 51:174-187

Brigham LA, Woo HH, Wen F, Hawes MC (1998) Meristem-specific suppression of mitosis and a global switch in gene expression in the root cap of pea by endogenous signals. Plant Physiol 118:1223-1231

Brisson LF, Tenhaken R, Lamb C (1994) Function of oxidative crosslinking of cell wall structural proteins in plant disease resistance. Plant Cell 6:1703-1712

Callaghan T, Benziman M (1984) High rates of in vitro synthesis of 1,4-beta-D-glucan in cell-free preparations from Phaseolus vulgaris. Nature 311:165-169 
Carpita NC, Gibeaut DM (1993) Structural models of primary cell walls in flowering plants: consistency of molecular structure with the physical properties of the walls during growth. Plant $\mathrm{J}$ 3:1-30

Carpita N, Tierney M, Campbell M (2001) Molecular biology of the plant cell wall: searching for the genes that define structure, architecture, and dynamics. Plant Mol Biol 47:1-5

Cassab G, Varner JE (1988) Cell wall proteins. Annu Rev Plant Physiol Plant Mol Biol 39:321-353

Cosgrove DJ (2005) Growth of the plant cell wall. Nat Rev Mol Cell Biol 6:850-861

Dhugga KS (2005) Plant Golgi cell wall synthesis: from genes to enzyme activities. PNAS 102:1815-1816

Faik A, Desveaux D, Maclachlan G (1997) Xyloglucan galactosyland fucosyl-transferase activities from pea epicotyl microsomes. Plant Physiol 114:245-254

Faik A, Bar-Peled M, DeRocher AE, Zeng W, Perrin RM, Wilkerson C, Raikhel NV, Keegstra K (2000) Biochemical characterization and molecular cloning of an $\alpha-1,2$-fucusyltransferase that catalyzes the last step of cell wall xyloglucan biosynthesis in pea. J Biol Chem 275:15082-15089

Feldman LJ (1984) Development and dynamics of the root apical meristem. Am J Bot 7:1308-1314

Freshour G, Clay RP, Fuller MS, Albersheim P, Darvill AG, Hahn MG (1996) Developmental and tissue-specific structural alterations of the cell wall polysaccharides of Arabidopsis thaliana roots. Plant Physiol 110:1413-1429

Freshour G, Bonin CP, Reiter WD, Albersheim P, Darvill AG, Hahn MG (2003) Distribution of fucose-containing xyloglucans in cell walls of the murl mutant of Arabidopsis. Plant Physiol 4:16021612

Fry SC (1989) The structure and functions of xyloglucan. J Exp Bot 40:1-11

Fry SC, Aldington S, Hetherington PR, Aitken J (1993a) Oligosaccharides as signals and substrates in the plant cell wall. Plant Physiol 103:1-5

Fry SC, York WS, Albersheim P, Darvill A, Hayashi T, Joseleau J-P, Kato Y, Lorences EP, Maclachlan GA, McNeil M, Mort AJ, Reid JSG, Seitz HU, Selvendran RR, Voragen AGJ, White AR (1993b) An unambiguous nomenclature for xyloglucan-derived oligosaccharides. Physiol Plant 89:1-3

Guillen R, York WS, Pauly M, An J, Impallomeni G, Albersheim P, Darvill AG (1995) Metabolism of xyloglucan generates xylosedeficient oligosaccharide subunits of this polysaccharide in etiolated peas. Carbohydr Res 277:291-311

Hawes MC (1983) Sensitivity of isolated oat root cap cells and protoplasts to victorin. Physiol Plant Pathol 22:65-76

Hawes MC, Lin H-J (1990) Correlation of pectolytic enzyme activity with the programmed release of cells from root caps of pea. Plant Physiol 94:1855-1859

Hawes MC, Bengough G, Cassab G, Ponce G (2003) Root caps and rhizosphere. J Plant Growth Regul 21:352-367

Hayashi T (1989) Xyloglucans in the primary cell wall. Ann Rev Plant Physiol Plant Microbiol 40:139-168

Hayashi T (1991) Biochemistry of xyloglucans in regulating cell elongation and expnasion. In: The cytoskeletal basis of plant growth and form. Academic Press, Dublin, pp 131-144

$\mathrm{Hu}$ Z, Du M (2006) Hairy root and its application in plant genetic engineering. J Integr Biol 48:121-127

Johansen JN, Vernhettes S, Hofte H (2006) The ins and outs of plant cell walls. Curr Opin Plant Biol 9:616-621

Kamra P, Gokhale RS, Mohanty D (2005) SEARCHGTr: a program for analysis of glycosyltrasnferases involved in glycosylation of secondary metabolites. Nucleic Acids Res 33:W220-W225

Kauss H, Hassid WZ (1967) Enzymic introduction of the methyl ester groups of pectin. J Biol Chem 242:3449-3453
Keller B, Sauer N, Lamb CJ (1988) Glycine-rich cell wall proteins in bean: gene structure and association of the protein with the vascular system. EMBO J 7:3623-3633

Knee EM, Gong FC, Gao MS, Teplitski M, Jones AR, Foxworth A, Mort AJ, Bauer WD (2001) Root mucilage from pea and its utilization by rhizosphere bacteria as a sole carbon source. Mol Plant Microbe Interact 14:775-784

Lerouxel O, Choo TS, Seveno M, Usadel B, Faye L, Lerouge P, Pauly M (2002) Rapid structural phenotyping of plant cell wall mutants by enzymatic oligosaccharide fingerprinting. Plant Physiol 130:1754-1763

Lerouxel O, Cavalier DM, Liepman AH et al (2006) Biosynthesis of plant cell wall polysaccharides-a complex process. Curr Opin Plant Biol 9:621-630

Lin L-S, Yuen HK, Varner JE (1991) Differential scanning calorimetry of plant cell walls. PNAS 88:2241-2243

Maldonado-Mendoza IE, Dewbre GR, Blaylock L, Harrison MJ (2005) Expression of a xyloglucan endotransglucosylast/hydrolase gene, Mt-XTH1, from Medicago truncatula is induced systematically in mycorrhizal roots. Gene 345:191-197

McCann MC, Roberts K (1991) Architecture of the primary cell wall. In: The cytoskeletal basis of plant growth and form. Academic Press, Dublin, pp 109-129

McDougall GJ, Fry SC (1989) Anti-auxin activity of xyloglucan oligosaccharides: the role of groups other than the terminal alpha-L-fucose residue. J Exp Bot 40:233-239

McDougall GJ, Fry SC (1990) Xyloglucan oligosaccharides promote growth and activate cellulose. Evidence for a role of cellulose in cell expansion. Plant Physiol 93:1042-1048

McQueen-Mason S, Durachko DM, Cosgrove DJ (1992) Two endogenous proteins that induce cell wall extension in plants. Plant Cell 4:1425-1433

Mejias-Luque R, Lopez-Ferrer A, Garrido M, Fabra A, de Bolos C (2007) Changes in the invasive and metastatic capacities of HT29/M3 cells induced by the expression of fucosyltransferase 1 . Cancer Sci 98:1000-1005

Nicoll SM, Brigham LA, Wen FS, Hawes MC (1995) Expression of transferred genes during hairy root development in pea. Plant Cell Tissue Organ Cult 42:57-66

Ookawara R, Satoh S, Yoshioka T, Ishizawa K (2005) Expression of alpha-expansin and xyloglucan endotransglucosylase/hydrolase genes associated with shoot elongation enhanced by anoxia, ethylene and carbon dioxide in arrowhead (Sagittaria pygmaea Miq.) tubers. Ann Bot 96:693-702

Pauly M, Albersheim P, Darvill A, York W (1999) Molecular domains of the cellulose/xyloglucan network in the cell walls of higher plants. Plant J 20:629-639

Pauly M, Qin Q, Greene H, Albersheim P, Darvill A, York WS (2001a) Changes in the structure of xyloglucan during cell elongation. Planta 212:842-850

Pauly M, Eberhard S, Albersheim P, Darvill A, York WS (2001b) Effects of the murl mutation on xyloglucans produced by suspension-cultured Arabidopsis thaliana cells. Planta 214:6774

Perrin RM, DeRocher AE, Bar-Peled M, Zeng W, Norambuena L, Orellana A, Raikhel NV, Keegstra K (1999) Xyloglucan fucosyltransferase, an enzyme involved in plant cell wall biosynthesis. Science 284:1976-1979

Perrin RM, Jia Z, Wagner TA, O’Neill MA, Sarria R, York WS, Raikhel NV, Keegstra K (2003) Analysis of xyloglucan fucosylation in Arabidopsis. Plant Physiol 32:768-778

Popper ZA, Fry SC (2005) Widespread occurrence of a covalent linkage between xyloglucan and acidic polysaccharides in suspension-cultured angiosperm cells. Ann Bot 96:91-99

Puhlmann J, Bucheli E, Swain MJ, Dunning N, Albersheim P, Darvill AG, Hahn MG (1994) Generation of monoclonal antibodies 
against plant cell wall polysaccharides: I. Characterization of a monoclonal antibody to a terminal (1-2)-linked fucosyl-containing epitope. Plant Physiol 104:699-710

Reiter W-D, Chapple CCS, Somerville CR (1993) Altered growth and cell walls in a fucose-deficient mutant of Arabidopsis. Application to a fucose-deficient mutant. Science 261:1032-1035

Reiter W-D, Chapple CCS, Somerville CR (1997) Mutants of Arabidopsis thaliana with altered cell wall polysaccharide composition. Plant J 12:335-345

Romo S, Jimenez T, Labrador E, Dopico B (2005) The gene for a xyloglucan endotransglucosylase/hydrolase from Cicer arietinum is strongly expressed in elongation tissues. Plant Physiol Biochem 43:169-176

Sambrook J, Fritsch EF, Maniatis T (1989) Molecular cloning: a laboratory manual, 2nd edn. Cold Spring Harbor Laboratory Press, USA, pp 1.38-1.39

Sarria R, Wagner TA, O’Neill MA, Faik A, Wilkerson CG, Keegstra K, Raikhel NV (2001) Characterization of a family of Arabidopsis genes related to xyloglucan fucosyltransferase 1. Plant Physiol 127:1595-1606

Satiat-Jeunemaitre B, Martin B, Hawes C (1992) Plant cell wall architecture is revealed by rapid-freezing and deep-etching. Protoplasma 168:33-42

Selvendran RR (1975) Analysis of cell wall material from plant tissues: extraction and purification. Phytochem 14:1011-1017

Somerville C, Bauer S, Brininstool G (2004) Towards a systems approach to understanding plant cell walls. Science 306:22062211

Takeda T, Furuta Y, Awano T, Mizuno K, Mitsuishi Y, Hayashi T (2002) Suppression and acceleration of cell elongation by integration of xyloglucans in pea stem segments. PNAS 99:9055-9060

Terry ME, Jones RL, Bonner BA (1981) Soluble cell wall polysaccharides released from pea stems by centrifugation. Plant Physiol 68:531-537

van Hengel AJ, Roberts K (2002) Fucosylated arabinogalactanproteins are required for full root cell elongation in arabidopsis. Plant J 32:105-113

Van Loon LC, Rep M, Pieterse CMJ (2006) Significance of inducible defense-related proteins in infected plants. Ann Rev Phytopathol 44:135-362

Vanzin GF, Madson M, Carpita NC, Raikhel NV, Keegstra K (2002) The mur2 mutant of Arabidopsis thaliana lacks fucosylated xyloglucan because of a lesion in fucosyltransferase AtFUT1. PNAS 99:3340-3345
Varner JE, Lin L-S (1989) Plant cell wall architecture. Cell 56:231239

Wen F, Zhu Y, Hawes MC (1999) Effect of pectin methylesterase gene expression on pea root development. Plant Cell 11:129 1140

Wen FS, Woo HH, Hirsch AM et al (2004) Lethality of inducible, meristem-localized ectopic beta-glucuronidase expression in plants. Plant Mol Biol Rep 22:7-14

Wen F, Laskowski M, Hawes MC (2005) Cell separation in roots. In: Roberts J, Gonzalez-Carranza Z (eds) Plant cell separation and adhesion. Blackwell, Oxford

Wen F, VanEtten HD, Tsaprailis G, Hawes MC (2007) Extracellular proteins in pea root tip and border cell exudates. Plant Physiol 143:773-783

Woo HH, Hawes MC (1997) Cloning of genes whose expression is correlated with mitosis and localized in dividing cells in root caps of pea. Plant Mol Biol 35:1045-1051

Woo HH, Orbach JM, Hirsch AM, Hawes MC (1999) Meristemlocalized inducible expression of a UDP-glycosyltransferase gene is essential for growth and development in pea and alfalfa. Plant Cell 11:303-2315

Woo HH, Faull KF, Hirsch AM et al (2003) Altered life cycle in Arabidopsis plants expressing PsUGT1, a UDP-glucuronosyltransferase-encoding gene from pea. Plant Physiol 133:538-548

Woo HH, Byeong RJB, Hirsch AM et al (2007) Characterization of Arabidopsis AtUGT85A and AtGUS gene families and their expression in rapidly dividing tissues. Genomics 90:143-153

Ye ZH, York WS, Darvill AG (2006) Important new players in secondary wall synthesis. Trends Plant Sci 11:162-164

York WS, Darvill AG, Albersheim P (1984) Inhibition of 2,4-Dstimulated elongation of pea stem segments by a xyloglucan fragment. Plant Physiol 75:95-297

Zablackis E, York WS, Pauly M, Hantus S, Reiter WD, Chapple CCS, Albersheim P, Darvill A (1996) Substitution of L-fucose by Lgalactose in the cell wall of Arabidopsis murl. Science 272:808 1810

Zhu Y, Wen F, Zhao X et al (2004) Isolation of the promoter of a root cap expressed pectinmethylesterase gene from Pisum sativum L. (rcpme1) and its use in the study of gene activity. Plant Soil 265:47-59

Zhu J, Chen S, Alvarez S, Asirvatham VS, Schachtman DP, Wu Y, Sharp RE (2006) Cell wall proteome in the maize primary root elongation zone. Plant Physiol 140:311-325 